\title{
ÁP DỤNG MÔ HİNH THỦY VĂN, THỦY LỬC MÔ PHỎNG NGẬP LỤT HẠ DU SÔNG CẢ
}

\section{Nguyễn Xuân Tiến ${ }^{1}$, Nguyễn Thanh $\operatorname{Sơn}^{2}$, Nguyễn Văn $\operatorname{Linh}^{3}$}

Tóm tắt: Dưới tác động của biến đổi khi hậu và sự phát triển của hệ thống hồ chứa thủy lợi, thủy điện ở thượng nguồn, vấn đề ngập lụt ở hạ du lưu vực sông Cả ngày càng nghiêm trọng. Nghiên cúu xác định nguyên nhân gây ngập lụt để đưa ra các giải pháp phù hợp nhằm giảm nhẹ thiệt hại là vấn đề cấp thiết hiện nay. Bài báo này trình bày viẹc áp dụng bộ mô hình MIKE (MIKE NAM, MIKE 11 và MIKE 21) để xây dựng mô hình mô phỏng và tính toán định lượng mưa gây ngập lụt vùng hạ du lưu vục sông Cả. Nghiên cưu đã sủ dụng bộ số liệu khí tuợng thủy văn 14 năm (2005 - 2018) của 30 trạm với thời đoạn muxa 6 giờ để hiệu chỉnh và kiểm định mô hình. Quá trình mực nước tính toán và thực đo tại 03 điểm so sánh phù hợp nhau, độ lón và thời gian xuất hiện đỉnh lũ gần nhau ( $\Delta H$ $<0,3 \mathrm{~m}$ ), hệ số Nash đều đạt được trị số cao (Nash> 0,89). Nghiên cứu đã tính toán được lương mua bắt đầu gây ngập, ngập ở các mức báo động lũ (Mức báo động 2 và 3) trong điều kiện tụ nhiên và có sự tác động của hồ chứa trên hệ thống sông Cả.

Từ khóa: Sông Cả, mô hình MIKE NAM, MIKE 11, MIKE 21, ngập lụt.

Ban Biên tập nhận bài: 12/10/2019 Ngày phản biện xong: 05/12/2019 Ngày đăng bài: 25/01/2020

\section{1. Đặt vấn đề}

Hiện nay, với sự phát triển nhanh chóng của công nghệ số đã tạo nên những công cụ đắc lực để mô phỏng toàn bộ các quá trình ngoài thực tế bằng các biểu thức toán học, chính là mô hình hóa toán học. Dựa vào hệ phương trình SaintVernat, nhiều mô hình thủy lực đã mô phỏng các quá trình dòng chảy. Trên thế giới, việc áp dụng mô hình thủy lực để tính toán ngập lụt đã được sử dụng rất rộng rãi. Knebla và cs (2005) [11] đã nghiên cứu mô hình HEC-HMS/RAS mô phỏng ngập lụt qui mô lớn ở lưu vực sông San Antonio, (khoảng 10.000 km2) ở trung tâm Texas, Mỹ. Nielsen (2006) đã ứng dụng mô hình MIKE SHE để tính toán ngập lụt vùng đồng bằng và tiêu thoát nước đô thị [13]. Nguyen Mai Dang (2010) [12], Tran Tho Dat (2019) [2], sử dụng bộ mô hình MIKE để mô phỏng ngập lụt vùng sông Đáy. Pathirama và cs (2011) đã phát triển mô hình EPA-SWMM5 để tính toán ngập lụt đô thị cho một lưu vực tại Brazil [14]. Tomkratoke và Sirisup (2015) đã dùng mô hình thủy động lực học FVCOM để mô phỏng ngập lụt vùng nghiên cứu [15]. Trong nước, việc sử dụng các mô hình thủy lực để tính toán ngập lụt cũng rất rộng rãi. Hoàng Thanh Tùng (2011) [8] đã sử dụng mô hình HEC-RAS để tính toán lũ cho lưu vực sông Cả. Trần Duy Kiều (2012 ) [3], Nguyễn Thanh Sơn và cs (2014) [6], Hoàng Thị Nguyệt Minh (2014) [5], Lương Tuấn Anh và cs (2015) [1], Nguyễn Thị Mai Linh và cs (2018) [4], Trần Hồng Thái và cs (2019) [7] đã sử dụng bộ mô hình MIKE để mô phỏng ngập lụt. Trong những năm gần đây liên tục xảy ra các trận lũ gây ngập lụt hạ du sông Cả, đặc biệt năm 2002, 2010 và 2013. Ngập lụt đã gây nhiều thiệt hại về người và của cho nhân dân. Bên cạnh đó nhiều hồ chứa thủy điện được đưa vào vận hành như: Bản Vẽ, Nậm Nơn, Nậm Mô, Bản Ang, Nhạn Hạc A, Châu Thắng, Ngàn Trươi và Hố Hô. Vấn đề nghiên cứu về ngập lụt để đưa ra các giải pháp hữu hiệu cho việc giảm nhẹ thiệt hại do ngập lụt gây ra là một yêu cầu cấp bách hiện nay. Vì vậy, nghiên cứu đã lựa chọn bộ mô hình MIKE để mô phỏng ngập lụt cho hạ du sông Cả, tính toán các kịch bản ngập lụt ở hạ du do mưa lớn và xả lũ

${ }^{1}$ Đài Khí tương Thủy văn khu vục Bắc Trung Bộ

${ }^{2}$ Khoa Khi tuợng Thủy văn và Hải durong họ, ĐH Khoa học Tụ nhiên

${ }^{3}$ Khoa Thủy văn và Tài nguyên nước, Đại học Thủy lợi

Email: tien1967@gmail.com 


\section{BÀI BÁO KHOA HỌC}

của hệ thống hồ chứa trên thượng nguồn gây ra.

2. Phương pháp nghiên cứu và thu thập dữ liệu

\subsection{Tổng quan về khu vực nghiên cứu}

Lưu vực sông Cả trải dài từ $18^{\circ} 15^{\prime} 50^{\prime \prime}$ đến $20^{\circ} 10^{\prime} 30^{\prime \prime}$ vĩ độ Bắc, từ $103^{\circ} 45^{\prime} 10^{\prime \prime}$ đến $105^{\circ} 15^{\prime} 20^{\prime \prime}$ kinh độ Đông. Phía Bắc giáp lưu vực sông Chu, phía Tây giáp lưu vực sông Mê Công, phía Nam giáp lưu vực sông Gianh và phía Đông giáp Biển Đông. Tổng diện tích lưu vực là $27.200 \mathrm{~km}^{2}$, phần diện tích ở Việt Nam là 17.730 $\mathrm{km}^{2}$, chiếm $65,2 \%$ diện tích lưu vực. Diện tích thuộc Lào là $9.470 \mathrm{~km}^{2}$ chiếm 34,8\% diện tích lưu vực. Dòng chính sông Cả có chiều dài 531 $\mathrm{km}$, trong đó $170 \mathrm{~km}$ chảy qua lãnh thổ Lào và qua địa phận Nghệ An - Hà Tĩnh là 361 km (Hình 1).

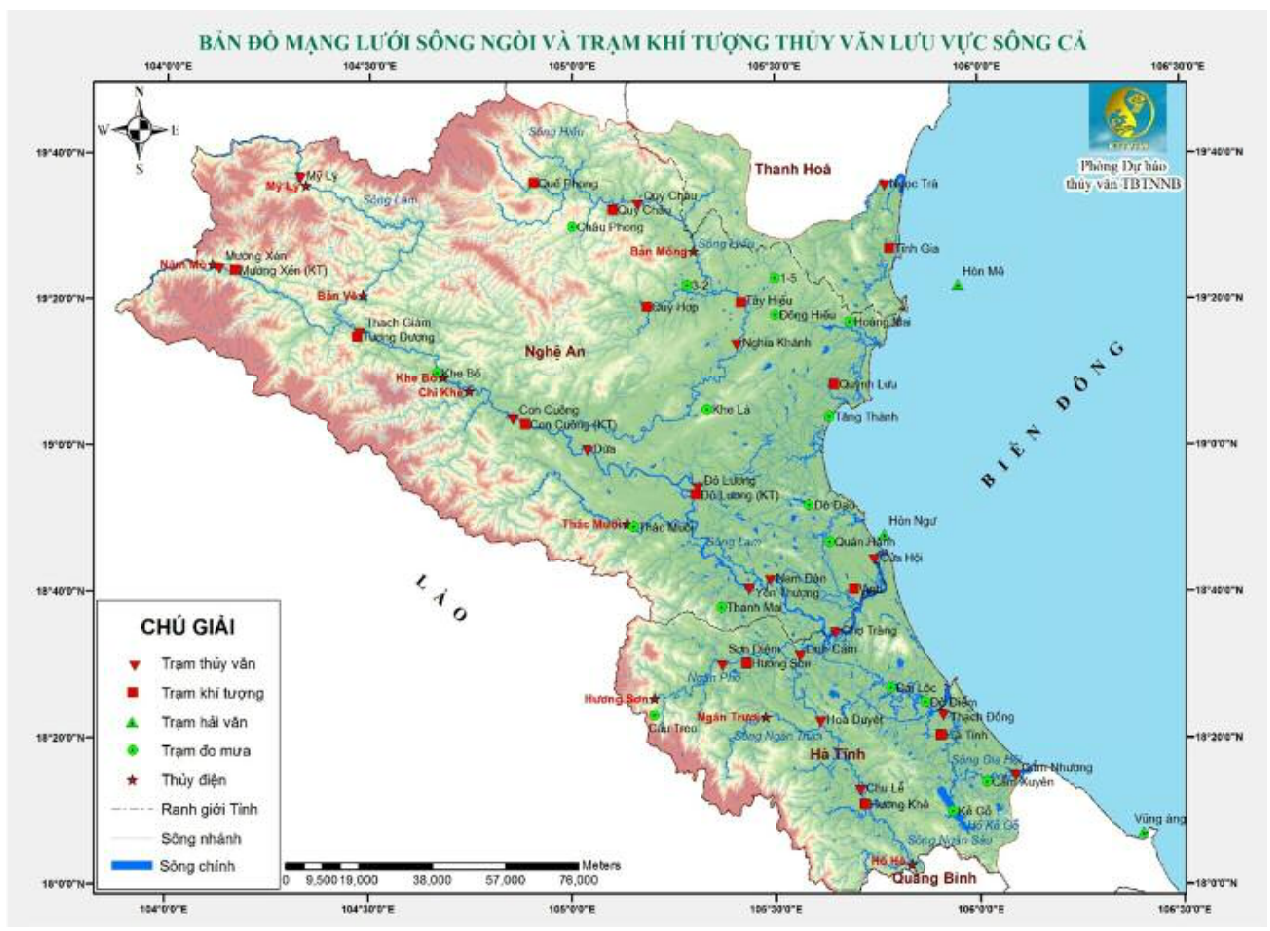

Hình 1. Bản đồ lưu vực sông Cả trên lãnh thổ Việt Nam

Các sông suối đổ vào dòng chính đều ngắn và dốc bắt nguồn từ vùng núi cao thuộc các tỉnh Xiêng Khoảng (Lào), Nghệ An, Hà Tĩnh. Tổng số có 44 sông nhánh cấp I. Những sông nhánh lớn của sông Cả là Nậm Mộ, Huổi Nguyên, sông Hiếu, sông Giăng và sông La. Các sông này đóng góp lượng dòng chảy đáng kể vào dòng chính [8].

2.2. Giới thiệu về mô hình MIKE NAM, MIKE 11 và MIKE 21

Mô hình MIKE có sự tích hợp rất tốt với GIS, có các mô đun kết nối dễ dàng MIKE NAM, MIKE 11 và MIKE 21 để mô phỏng, tính toán ngập lụt vùng hạ lưu sông Cả.

\subsubsection{Mô hình MIKE NAM}

Mô hình MIKE NAM là mô hình dạng bể chứa dùng để tính toán dòng chảy từ mưa. Các bể chứa được sử dụng trong mô hình gồm: bể tuyết, bể chứa mặt, Bể sát mặt (bể tầng rễ cây) và bể chứa ngầm.

Thiết lập mô hình NAM: Căn cứ vào mạng lưới sông và vị trí của trạm đo mưa, lưu vực sông Cả được chia thành 60 lưu vực con. Sử dụng công cụ ArcGIS để số hóa, kết quả được bản đồ phân vùng lưu vưc như hình 2. 


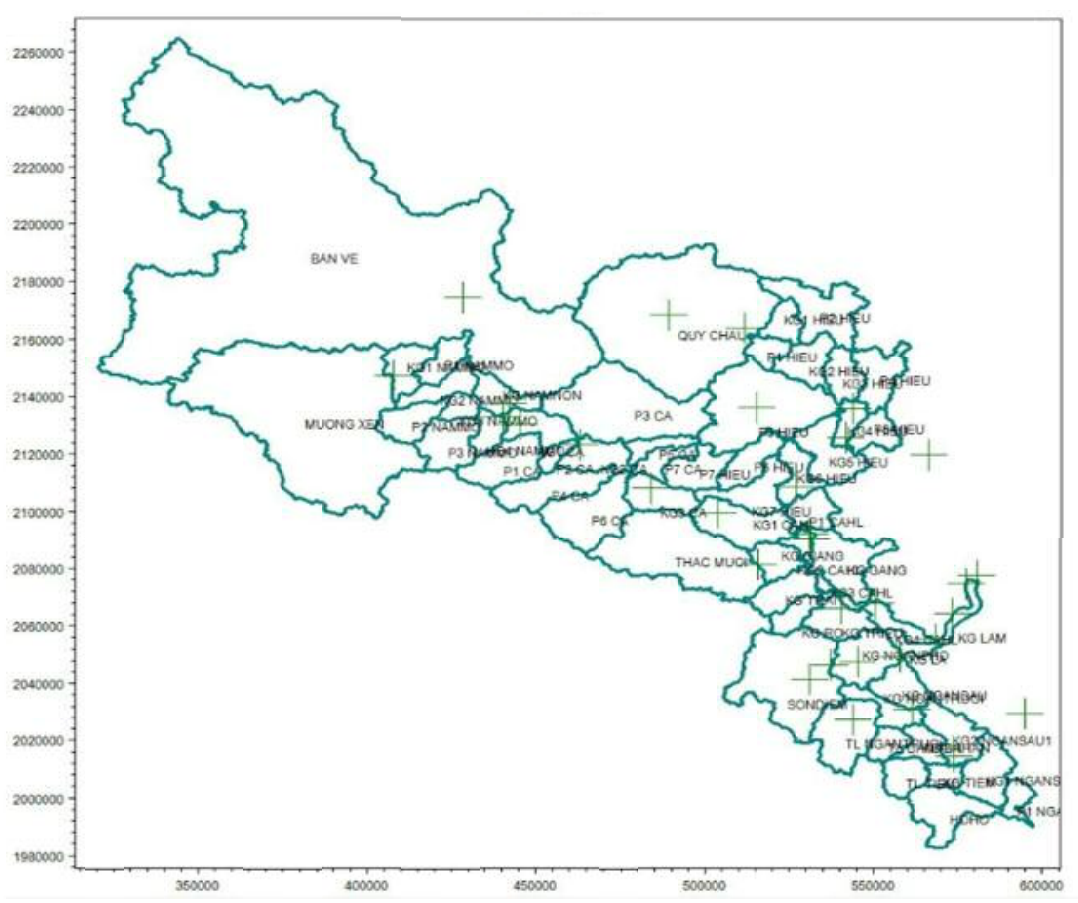

Hình 2. Phân vùng lưu vục con cho lưu vục sông Cả

\subsubsection{Mô hình MIKE 11}

Mô hình MIKE 11 do DHI Water \& Environment phát triển, là một gói phần mềm dùng để mô phỏng dòng chảy/ lưu lượng, chất lượng nước và vận chuyển bùn cát ở các cửa sông, sông, kênh tưới và các vật thể nước khác [13].

Mô hình MIKE 11 là mô hình tính toán mạng sông dựa trên việc giải hệ phương trình một chiều Saint-Venant:

Phương trình liên tục:

$$
\frac{\partial Q}{\partial x}+b \frac{\partial h}{\partial t}=0
$$

Phương trình chuyển động:

$$
\frac{\partial Q}{\partial t}+\frac{\partial\left(\alpha \frac{Q^{2}}{A}\right)}{\partial x}+g A \frac{\partial h}{\partial x}+\frac{g Q|Q|}{C^{2} A R}=0
$$

Trong đó: A là diện tích mặt cắt ngang $\left(\mathrm{m}^{2}\right)$; $\mathrm{t}$ là thời gian $(\mathrm{s})$; $\mathrm{Q}$ là lưu lượng nước $\left(\mathrm{m}^{3} / \mathrm{s}\right) ; \mathrm{x}$ là biến không gian; $\mathrm{g}$ là gia tốc trọng trường $\left(\mathrm{m} / \mathrm{s}^{2}\right) ; \rho$ là mật độ của nước $\left(\mathrm{kg} / \mathrm{m}^{3}\right)$; b là độ rộng của lòng dẫn $(\mathrm{m})$ và $\mathrm{R}$ là bán kính thủy lực $(\mathrm{m})$.

Các biên lưu lượng ở thượng nguồn gồm: Mường Xén, Bản Vẽ, Quỳ Châu, Thác Muối, Thanh Hương, Thanh Thủy, Thanh Mai, Cầu Om, Sơn Diệm, Hố Hô, Đá Hàn, Sơn Kim, Ngàn Trươi. Biên hạ lưu là mực nước tại trạm thủy văn Cửa Hội. Sơ đồ thủy lực một chiều sông Cả được thể hiện tại hình 3 . 


\section{BÀI BÁO KHOA HỌC}

Bảng 1. Thông tin đặc trung mang thủy lục $1 D$

\begin{tabular}{|c|c|c|c|c|c|}
\hline TT & Tên sông & $\begin{array}{c}\text { Chiều dài } \\
(\mathrm{km})\end{array}$ & $\begin{array}{l}\text { Số mặt } \\
\text { cắt }\end{array}$ & Điểm đầu & Điểm cuối \\
\hline 1 & Sông Cả & 255 & 223 & Cửa Rào & Cửa Hội \\
\hline 2 & Sông Nậm Mộ & 51 & 43 & Mường Xén & Cửa Rào \\
\hline 3 & $\begin{array}{l}\text { Sông Nậm } \\
\text { Nơn }\end{array}$ & 16 & 14 & Bản Vẽ & Cửa Rào \\
\hline 4 & Sông Hiếu & 105 & 48 & Quỳ Châu & Nhập lưu vào sông Cả \\
\hline 5 & Sông Giăng & 23 & 12 & Thác Muối & Nhập lưu vào sông Cả \\
\hline 6 & Sông Trai & 11 & 17 & Thanh Hương & Nhập lưu vào sông Cả \\
\hline 7 & Sông Rộ & 15 & 19 & Thanh Thủy & Nhập lưu vào sông Cả \\
\hline 8 & Hói Triều & 9 & 19 & Thanh Mai & Nhập lưu vào sông Cả \\
\hline 9 & Gang & 37 & 18 & Cầu Om & Nhập lưu vào sông Cả \\
\hline 10 & $\begin{array}{l}\text { Sông Ngàn } \\
\text { Phố }\end{array}$ & 30 & 16 & Sơn Diệm & Linh Cảm \\
\hline 12 & $\begin{array}{l}\text { Sông Ngàn } \\
\text { Sâu }\end{array}$ & 92 & 55 & Hố Hô & Linh Cảm \\
\hline 13 & Sông Hào & 6.25 & 4 & Sông La & Sông Cả \\
\hline 14 & Sông Tiêm & 16 & 20 & Kim Sơn & $\begin{array}{l}\text { Nhập lưu vào sông } \\
\text { Ngàn Sâu }\end{array}$ \\
\hline 15 & Sông Đá Hàn & 10 & 20 & Đá Hàn & $\begin{array}{l}\text { Nhập lưu vào sông } \\
\text { Ngàn Sâu }\end{array}$ \\
\hline 16 & $\begin{array}{l}\text { Sông Ngàn } \\
\text { Trươi }\end{array}$ & 19 & 35 & Ngàn Trươi & $\begin{array}{l}\text { Nhập lưu vào sông } \\
\text { Ngàn Sâu }\end{array}$ \\
\hline 17 & Sông La & 13 & 12 & Linh Cảm & Ngã ba Chợ Tràng \\
\hline
\end{tabular}

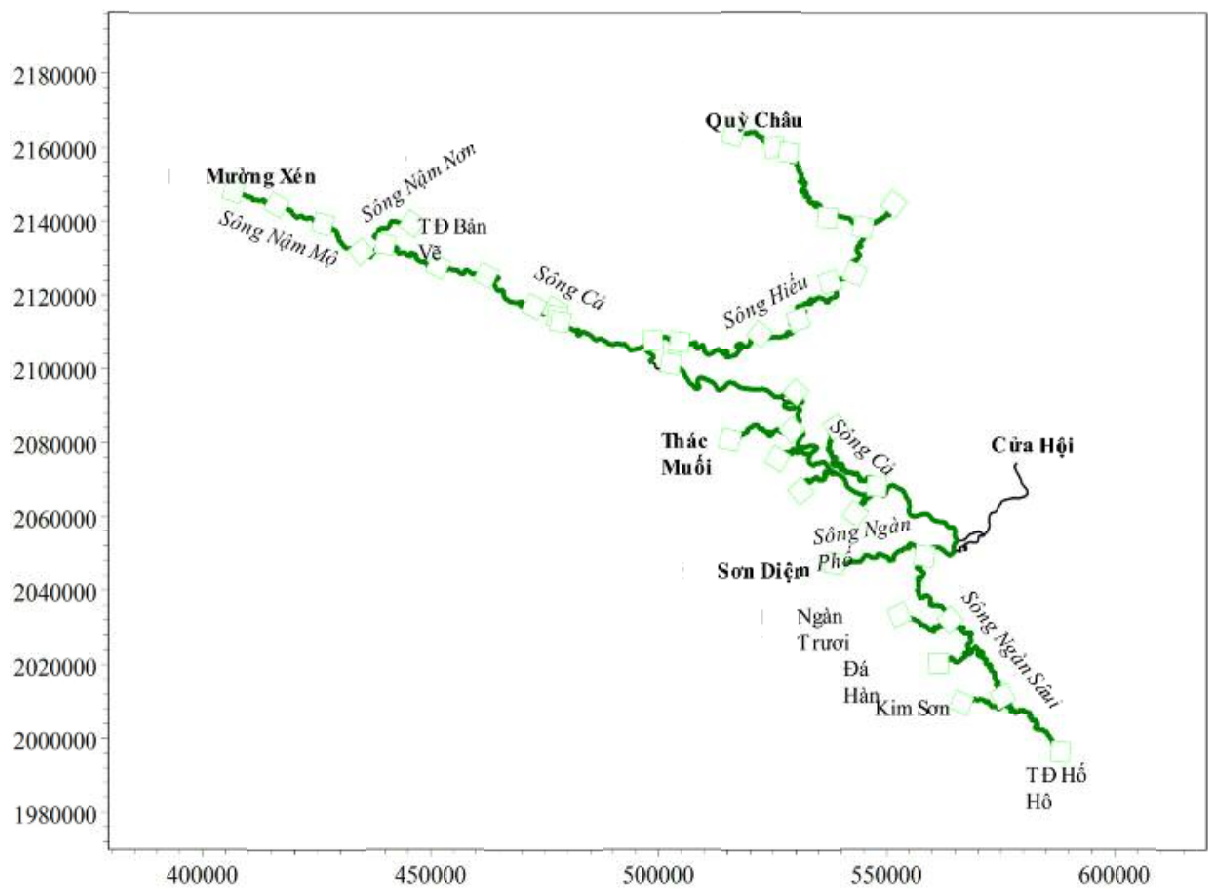

Hình 3. So đồ mạng lưới thủy lực một chiều sông Cả 


\subsubsection{Mô hình MIKE 21}

Mô hình MIKE 21 là một mô hình thuộc bộ chương trình MIKE do Viện Thủy lực Đan Mạch (DHI) phát triển, là một phần mềm dùng để mô phỏng dòng chảy, lưu lượng, chất lượng nước và vận chuyển bùn cát và các chất ô nhiễm ở các cửa sông, sông, hồ, biển và các khu vực chứa nước khác [12].

Mô đun dòng chảy được giải bằng phương pháp lưới phần tử hữu hạn. Mô đun này dựa trên nghiệm số của hệ các phương trình NavierStokes trung bình Reynolds cho chất lỏng không nén được 2 hoặc 3 chiều kết hợp với giả thiết Boussinesq và giả thiết áp suất thuỷ tĩnh. Do đó, mô đun bao gồm các phương trình: phương trình liên tục, động lượng, nhiệt độ, độ muối và mật độ và chúng được khép kín bởi sơ đồ khép kín rối. Với trường hợp ba chiều thì sử dụng xấp xỉ chuyển đổi hệ toạ độ sigma.

Phương trình liên tục:

$$
\frac{\partial \mathrm{u}}{\partial \mathrm{x}}+\frac{\partial v}{\partial \mathrm{y}}+\frac{\partial \mathrm{w}}{\partial \mathrm{z}}=\mathrm{S}
$$

Phương trình động lượng theo phương $\mathrm{x}$ và $\mathrm{y}$ tương ứng:

$\frac{\partial \mathrm{u}}{\partial \mathrm{t}}+\frac{\partial \mathrm{u}^{2}}{\partial \mathrm{x}}+\frac{\partial v \mathrm{u}}{\partial \mathrm{y}}+\frac{\partial \mathrm{wu}}{\partial \mathrm{z}}=$

$f v-g \frac{\partial \eta}{\partial x}-\frac{1}{\rho_{0}} \frac{\partial p_{a}}{\partial x}-\frac{g}{\rho_{0}} \int_{z}^{\eta} \frac{\partial \rho}{\partial x} d z+F_{u}+\frac{\partial}{\partial z}\left(v_{t} \frac{\partial u}{\partial z}\right)+u_{s} S$

$\frac{\partial v}{\partial \mathrm{t}}+\frac{\partial v^{2}}{\partial \mathrm{y}}+\frac{\partial v \mathrm{u}}{\partial \mathrm{x}}+\frac{\partial \mathrm{w} v}{\partial \mathrm{z}}=$

$-f u-g \frac{\partial \eta}{\partial y}-\frac{1}{\rho_{0}} \frac{\partial p_{a}}{\partial y}-\frac{g}{\rho_{0}} \int_{z}^{\eta} \frac{\partial \rho}{\partial y} d z+F_{v}+\frac{\partial}{\partial z}\left(v_{t} \frac{\partial v}{\partial z}\right)+v_{s} S$

Trong đó $\mathrm{t}$ là thời gian; $\mathrm{x}, \mathrm{y}$ và $\mathrm{z}$ là toạ độ Đề các; $\eta$ là dao động mực nước; $d$ là độ sâu; $\mathrm{h}=\eta+\mathrm{d}$ là độ sâu tổng cộng; $\mathrm{u}, \mathrm{v}$ và $\mathrm{w}$ là thành phần vận tốc theo phương $\mathrm{x}, \mathrm{y}$ và $\mathrm{z} ; \mathrm{f}=2 \Omega \sin \phi$ là tham số Coriolis; $\mathrm{g}$ là gia tốc trọng trường; $\rho$ là mật độ nước; là nhớt rối thẳng đứng; $\mathrm{p}_{\mathrm{a}}$ là áp suất khí quyển; $\rho_{\mathrm{o}}$ là mật độ chuẩn; $\mathrm{S}$ là độ lớn của lưu lượng do các điểm nguồn và $\left(\mathrm{u}_{\mathrm{s}}, \mathrm{V}_{\mathrm{s}}\right)$ là vận tốc của dòng lưu lượng đi vào miền tính. $\mathrm{Fu}$, $\mathrm{F}_{\mathrm{v}}$ là các số hạng ứng suất theo phương ngang.

\subsection{Kết nối giữa MIKE 11 và MIKE 21}

Dòng chảy trong vùng ngập lụt là dòng chảy
2 chiều theo phương ngang, vừa có dòng chảy tập trung trong các mạng lưới sông suối vừa có dòng chảy tràn trên bề mặt, do vậy nếu sử dụng mô hình 2 chiều để mô phỏng quá trình này thì yêu cầu lưới tính khá chi tiết để mô tả đủ chính xác ảnh hưởng của dòng chảy tập trung trong các kênh, rãnh. Mặt khác, dòng chảy tràn trên bề mặt chỉ xuất hiện khi có mực nước trong sông cao hơn cao trình bờ (hoặc đê), vì thế để giảm thời gian và khối lượng tính toán có thể kết hợp các ưu điểm của cả mô hình 1 và 2 chiều bằng cách kích hoạt mô đun tính toán 2 chiều khi xuất hiện dòng chảy tràn. Mô hình MIKE FLOOD thực hiện các kết nối giữa mô hình MIKE 11 (tính toán thủy lực mạng sông 1 chiều) với mô hình MIKE 21 (mô phỏng dòng chảy nước nông 2 chiều theo phương ngang) bằng 4 loại kết nối:

- Kết nối tiêu chuẩn: sử dụng khi một nhánh sông một chiều đổ trực tiếp vào vùng ngập 2 chiều;

- Kết nối bên: sử dụng khi một nhánh sông nằm kề vùng ngập, và khi mực nước trong sông cao hơn cao trình bờ thì sẽ kết nối với ô lưới tương ứng của mô hình 2 chiều;

- Kết nối công trình (ẩn): sử dụng các dạng liên kết qua công trình;

- Kết nối khô (zero flow link): là kết nối không cho dòng chảy tràn qua.

Nghiên cứu đã tiến hành xây dựng lưới tính cho miền tính 2 chiều bao gồm các bãi chứa lũ dọc theo các sông từ trạm các vị trí ở thượng nguồn: Dừa, Sơn Diệm, Hố Hô, Đá Hàn, Ngàn Trươi và Tiêm ra đến cửa biển. Khu vực nghiên cứu với diện tích là $3200 \mathrm{~km} 2$ được rời rạc hóa thành 89861 phần tử hữu hạn (FEM) với kích thước mỗi cạnh ô lưới từ 300-400 m cho khu vực có địa hình tương đối bằng phẳng, còn với những khu vực có sự thay đổi nhiều về địa hình như hệ thống giao thông, khu rìa các bờ sông, đê kè, hay các khu dân cư thì lưới tính nhỏ hơn với kích thước thay đổi dần từ 50-100 m (hình 4). Sau khi xây dựng mạng lưới thủy lực trong Mike 11 và Mike 21 nghiên cứu tiến hành Coupling 2 mạng lưới thủy lực 1 chiều và 2 chiều, các liên kết bên được lựa chọn để kết nối 2 mô hình.

Với mạng lưới thủy lực 1 và $2 \mathrm{D}$ xây dựng được, nghiên cứu tiến hành kết nối giữa mô hình 1\&2D trong mô hình MIKE FLOOD để tính toán ngập lụt vùng nghiên cứu. 




Hình 4. Miền tính, lưới tính 2 chiều cho vùng nghiên cưu

\subsection{Tài liệu sử dụng nghiên cứu}

- Tài liệu khí tượng thủy văn (KTTV): sử dụng gồm 30 trạm, trong đó có 8 trạm đo lưu lượng nước, 7 trạm đo mực nước, 15 trạm đo lượng mưa. Nếu sử dụng số liệu mưa 1 ngày thì số năm có số liệu đồng bộ là 50 năm (19691918). Nghiên cứu này đã sử dụng 14 năm số liệu (2005 - 2018) với thời đoạn mưa là 6 giờ để hiệu chỉnh và kiểm định mô hình. Số trận lũ trong 15 năm trên là 23 trận, trận lũ lớn nhất xuất hiện tháng $10 / 2010$ với đỉnh lũ là 4,96 m và trận lũ lớn nhất xuất hiện tháng 09/2019 với đỉnh lũ là 2,09 m tại Chợ Tràng. Riêng số liệu dùng để mô phỏng dòng chảy tại Cốc Nà bằng mô hình MIKE NAM chỉ có từ 1961-1976.

- Tài liệu địa hình là bản đồ DEM 1/10.000 do Dự án "Xây dựng xã hội thích ứng với thiên tai giai đoạn 2 - tỉnh Nghệ An" của tổ chức JICA cấp năm 2014; mặt cắt ngang trên các sông chính ở Nghệ An và Hà Tĩnh do Liên đoàn Khảo sát KTTV đo đạc năm 2001.

\section{Kết quả tính toán và thảo luận}

3.1. Hiệu chỉnh và kiểm định mô hình MIKE NAM 
Căn cứ vào số liệu thời đoạn $6 \mathrm{~h}$ trên lưu vực sông Cả, chúng tôi chọn 3 lưu vực để hiệu chỉnh và kiểm định: Quỳ Châu trên sông Hiếu $(\mathrm{F}=2010$ $\left.\mathrm{km}^{2}\right)$, Sơn Diệm trên sông Ngàn Phố $(\mathrm{F}=790$ $\left.\mathrm{km}^{2}\right)$, Cốc Nà trên Khe Choang $\left(\mathrm{F}=416 \mathrm{~km}^{2}\right)$.

\subsubsection{Luu vưc Quỳ Châu}

Lựa chọn các trận lũ để hiệu chỉnh và kiểm định mô hình:

- Hiệu chỉnh: trận lũ từ 12/9/2016-18/9/2016 có đỉnh lũ $\mathrm{Q}_{\max }=4270$;

- Kiểm định: trận lũ từ 14/9/2017-20/9/2017 có đỉnh lũ $\mathrm{Q}_{\max }=1790$.

Kết quả hiệu chỉnh và kiểm định thể tại hình $5 a-5 b$.

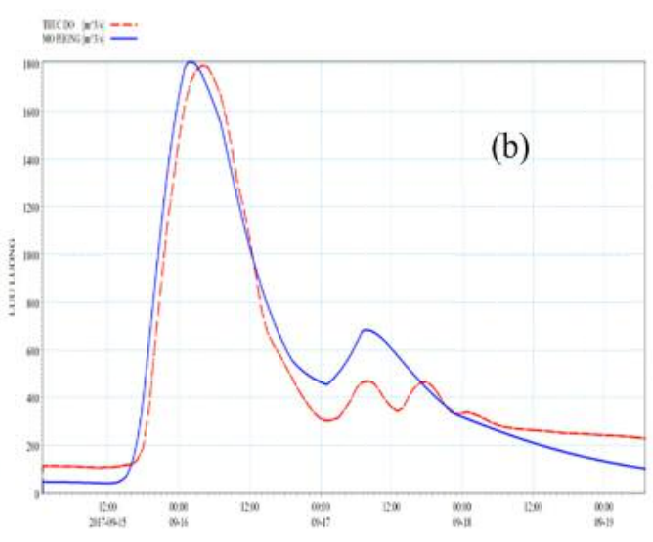

Hình 5. (a) Kết quả hiệu chỉnh luu luợng tại Quỳ Châu; (b) Kết quả kiểm định lưu luợng tại Quỳ Châu

\subsubsection{Lưu vục Son Diệm}

Lựa chọn các trận lũ để hiệu chỉnh và kiểm định mô hình:

- Hiệu chỉnh: trận lũ từ 02/10 - 09/10/2007 có đỉnh lũ $\mathrm{Q}_{\max }=1450$;

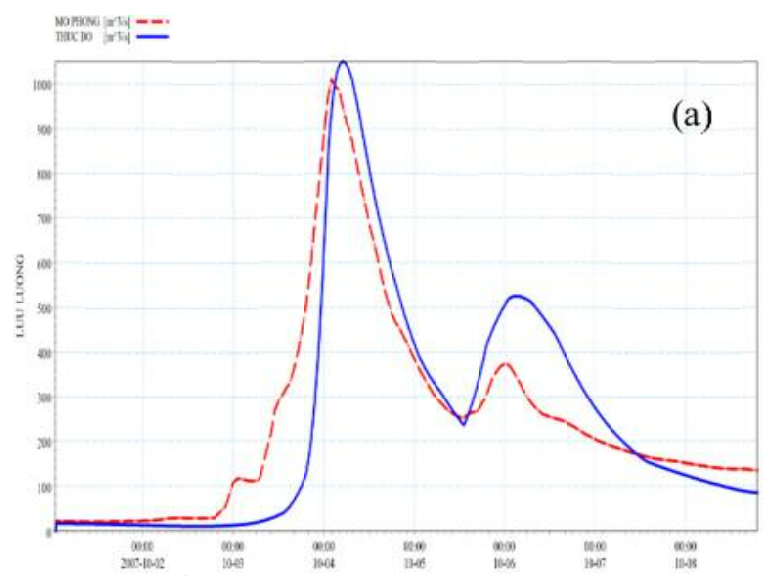

Hình 6. (a) Kết quả hiệu chỉnh luu luợng tại Son Diệm; (b) Kết quả kiểm định luu luợng tại Sơn Diệm

\subsubsection{Lư vực Cốc Nà:}

Lựa chọn các trận lũ để hiệu chỉnh và kiểm định mô hình:

- Hiệu chỉnh: trận 1 từ 04/9-12/9/1972 có đỉnh $\quad 7 \mathrm{a}-7 \mathrm{~b}$.
- Kiểm định: trận lũ từ 14/10 - 23/10/2013 có đỉnh lũ $\mathrm{Q}_{\max }=2340$.

Kết quả hiệu chỉnh và kiểm định thể tại hình $6 a-6 b$.

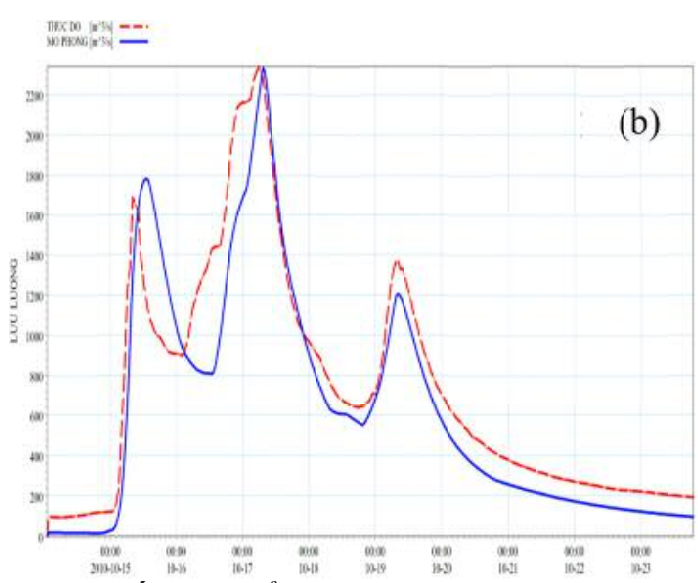

lũ $\mathrm{Q}_{\max }=807$; 


\section{BÀI BÁO KHOA HỌC}

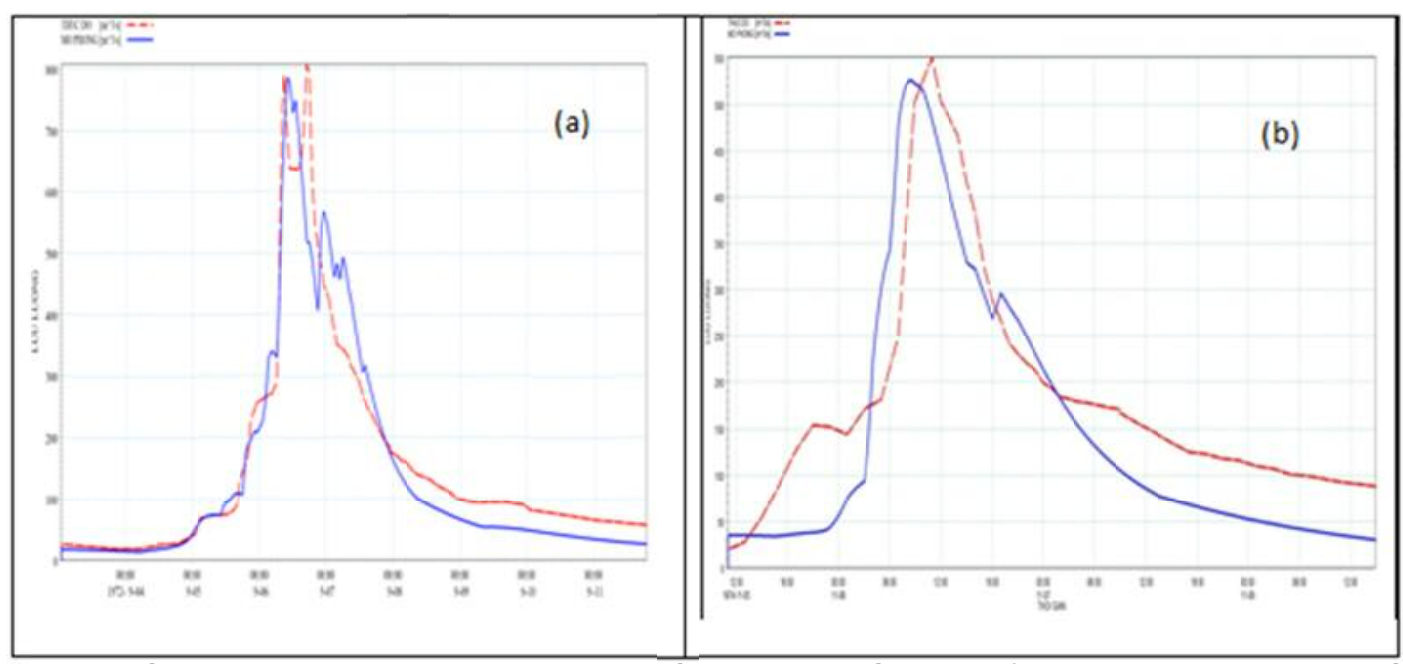

Hình 7. (a) Kết quả hiệu chỉnh luu lương tại Cốc Nà; (b) Kết quả kiểm định luu luợng tại Cốc Nà

Bảng 2. Tổng hợp kết quả hiệu chỉnh, kiểm định mô hình MIKE NAM

\begin{tabular}{|c|c|c|c|c|}
\hline Trạm thủy văn & Quá trình & Sai số Nash & $\begin{array}{c}\text { Sai số đỉnh lũ } \\
\Delta Q(\%)\end{array}$ & $\begin{array}{l}\text { Sai số tổng } \\
\text { lượng (\%) }\end{array}$ \\
\hline \multirow[t]{2}{*}{ Quỳ Châu } & $\begin{array}{c}\text { Hiệu chỉnh trận lũ } \\
09 / 2016\end{array}$ & 0,87 & -5.1 & $-5,2$ \\
\hline & $\begin{array}{c}\text { Kiểm định trận lũ } \\
09 / 2017\end{array}$ & 0,93 & +1.1 & $+4,4$ \\
\hline \multirow{2}{*}{ Sơn Diệm } & $\begin{array}{c}\text { Hiệu chỉnh trận lũ } \\
\text { 10/2007 }\end{array}$ & 0,79 & +3.8 & $+3,0$ \\
\hline & $\begin{array}{c}\text { Kiểm định trận lũ } \\
09 / 2010\end{array}$ & 0,86 & +0.2 & $+12,0$ \\
\hline \multirow{2}{*}{ Cốc Nà } & $\begin{array}{c}\text { Hiệu chỉnh trận lũ } \\
\text { 09/1972 }\end{array}$ & 0.9 & -1.2 & +7.5 \\
\hline & $\begin{array}{c}\text { Kiểm định trận lũ } \\
11 / 1974\end{array}$ & 0,78 & -4.2 & +18 \\
\hline
\end{tabular}

Bảng 3. Kết quả bộ thông số mô hình MIKE NAM các lưu vục nghiên cưu

\begin{tabular}{cccc}
\hline Thông số & Quỳ Châu & Sơn Diệm & Cốc Nà \\
\hline Umax & 15 & 20 & 16,2 \\
Lmax & 85 & 150 & 81,3 \\
CQOF & 0.45 & 0.6 & 0,904 \\
CKIF & 226 & 30 & 101,9 \\
CK1,2 & 11 & 20 & 18,2 \\
TOF & 0.4 & 0.4 & 0,873 \\
TIF & 0.01 & 0.01 & 0,511 \\
TG & 0.01 & 0.01 & 0,313 \\
CKBF & 1200 & 120 & 1502 \\
\hline
\end{tabular}


Kết quả hiệu chỉnh và kiểm định mô hình MIKE NAM tại 03 lưu vực (Quỳ Châu, Sơn Diệm và Cốc Nà) thuộc hệ thống sông Cả đều cho kết quả tốt: hệ số Nash đạt từ 0,78 đến 0,93 , sai số đỉnh lũ $\Delta \mathrm{Q}$ đạt từ và sai số tổng lượng đạt từ 3.0 đến $18 \%$. Đường quá trình thực đo và tính toán tương đối phù hợp, tại Quỳ Châu và Sơn Diệm cho kết quả tốt hơn. Vậy, kết quả bộ thông số mô hình tại bảng 3 có thể được sử dụng để tính toán dòng chảy từ mưa tại các lưu vực
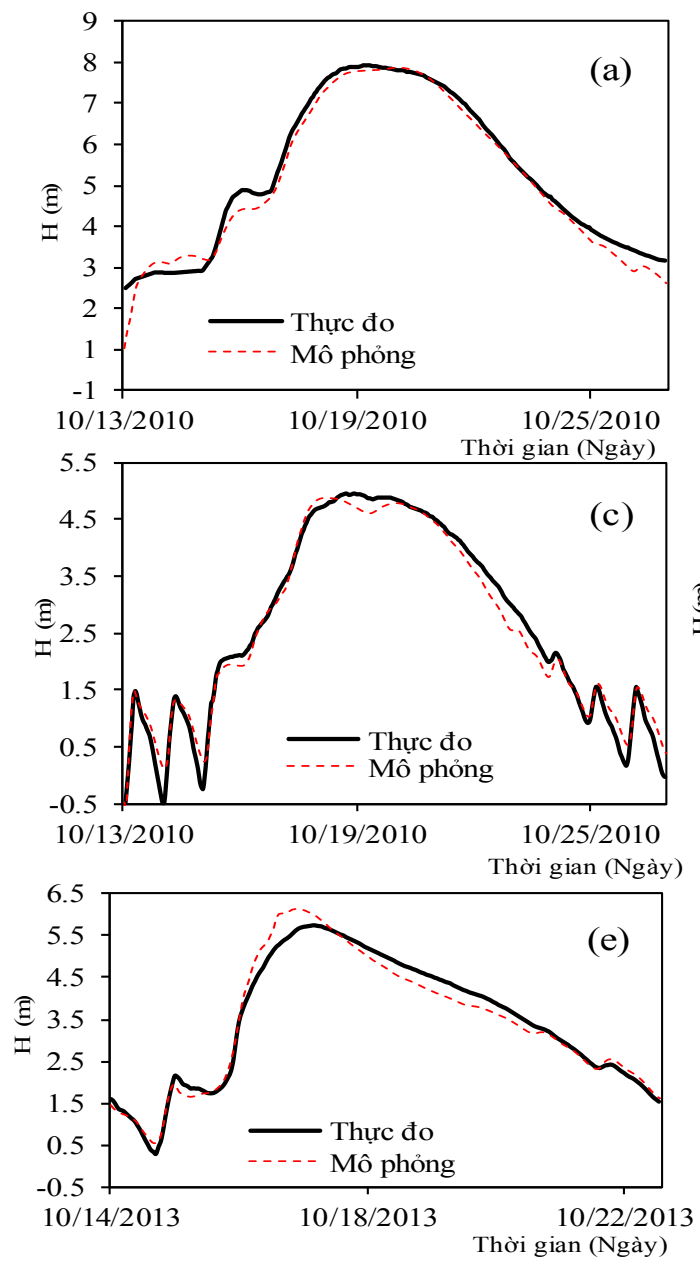

nghiên cứu trên và các lưu vực lân cận để tính toán đầu vào cho mô hình MIKE 11.

\subsection{Hiệu chỉnh và kiểm định mô hình MIKE} 11 và MIKE 21

Quá trình hiệu chỉnh mô hình được thực hiện qua trận lũ từ 15-26/10/2010. Vị trí để so sánh mực nước thực đo và tính toán tại 03 trạm thủy văn: Nam Đàn, Linh Cảm và Chợ Tràng. Kết quả thể hiện tại các hình $8 \mathrm{a}-8 \mathrm{f}$.


Hình 8. Kết quả hiệu chỉnh mục nước tại các trạm: Nam Đàn, Linh Cảm và Chọ Tràng (a-c) tù 15-26/10/2010; Kết quả hiệu chỉnh mực nước tại các trạm: Nam Đàn, Linh Cảm và Chọ Tràng (d-f) tì 14-23/10/2013 


\section{BÀI BÁO KHOA HỌC}

Bảng 4. Tổng hơp kết quả hiệu chỉnh, kiểm định tại trạm thủy văn Nam Đàn

\begin{tabular}{|c|c|c|c|c|}
\hline Trạm thủy văn & Quá trình & Sai số Nash & $\begin{array}{c}\text { Sai số đỉnh lũ } \\
\Delta H(\mathrm{~m})\end{array}$ & $\begin{array}{l}\text { Sai số tổng } \\
\text { lượng }(\%)\end{array}$ \\
\hline \multirow{2}{*}{ Nam Đàn } & $\begin{array}{c}\text { Hiệu chỉnh trận lũ } \\
\text { 10/2010 }\end{array}$ & 0,93 & $-0,11$ & $-1,8$ \\
\hline & $\begin{array}{c}\text { Kiểm định trận lũ } \\
\text { 10/2013 }\end{array}$ & 0,89 & $-0,09$ & $+7,4$ \\
\hline \multirow{2}{*}{ Linh Cảm } & $\begin{array}{c}\text { Hiệu chỉnh trận lũ } \\
\text { 10/2010 }\end{array}$ & 0,95 & $-0,02$ & $+4,7$ \\
\hline & $\begin{array}{c}\text { Kiểm định trận lũ } \\
\text { 10/2013 }\end{array}$ & 0,93 & $+0,31$ & +10 \\
\hline \multirow[t]{2}{*}{ Chợ Tràng } & $\begin{array}{c}\text { Hiệu chỉnh trận lũ } \\
\text { 10/2010 }\end{array}$ & 0,93 & $+0,3$ & $+1,5$ \\
\hline & $\begin{array}{c}\text { Kiểm định trận lũ } \\
\text { 10/2013 }\end{array}$ & 0,91 & $+0,1$ & $+2,6$ \\
\hline
\end{tabular}

Quá trình mực nước tính toán và thực đo tại 03 điểm Linh Cảm, Nam Đàn và Chợ Tràng khá phù hợp về xu thế, thời gian xuất hiện đỉnh. Trong đó tại Chợ Tràng là phù hợp nhất với hệ số Nash: 0,93 và 0,91 , sai số đỉnh lũ $\Delta \mathrm{H}:+0,30 \mathrm{~m}$ và $+0,10 \mathrm{~m}$, sai số tổng lượng: $+1,5 \%$ và $+2,6 \%$. Tuy nhiên, kết quả kiểm định tại điểm Nam Đàn còn sai lệch khá nhiều về thời gian xuất hiện đỉnh và quá trình mực nước ở sườn xuống. Đỉnh lũ tính toán xuất hiện sớm hơn và quá trình lũ ở sườn xuống cao hơn so với thực đo. Do những hạn chế về số liệu khí tượng thủy văn và số liệu địa hình trên lưu vực đã gây ra nhiều khó khăn cho việc mô phỏng lũ, ngập lụt trên lưu vực sông Cả. Mạng lưới trạm khí tượng thủy văn trên lưu vực sông Cả còn rất thưa $\left(15.880 \mathrm{~km}^{2} / 30\right.$ trạm $\approx$ $529 \mathrm{~km}^{2} /$ trạm) và thời đoạn mưa thực đo và tính toán còn lớn (6 giờ). Vì vậy, có thể sử dụng mô hình mô phỏng này để tính toán ngập lụt cho vùng hạ du lưu vực sông Cả.

\subsection{Tính toán ngâpp lụt vùng hạ du lưu vục sông $\boldsymbol{C a ̉}$}

3.3.1. Xác định điều kiện ban đầu của mô hình MIKE NAM tại các lưu vục nghiên cúu

Trong mô hình MIKE NAM, điều kiện ban đầu rất quan trọng. Nó ảnh hưởng khá lớn tới kết quả tính toán dòng chảy ở của ra của lưu vực. Sử dụng bộ thông số đã có ở bảng 3, xác định điều kiện ban đầu tại các lưu vực nghiên cứu ở các thời kỳ đầu mùa lũ, giữa mùa lũ và cuối mùa lũ. Qua nhiều trận lũ tại lưu vực Quỳ Châu và Sơn Diệm từ năm 2005 đến 2018, nhận thấy ở thời kỳ đầu vụ điều kiện ban đầu khá ổn định $\left(\mathrm{U} / \mathrm{U}_{\max }=0,3\right.$ và $\left.\mathrm{L} / \mathrm{L}_{\max }=0,3\right)$. Thời kỳ giữa vụ và cuối vụ điều kiện ban đầu thay đổi nhiều, phụ thuộc vào lượng mưa và thời gian mưa trước đó. VD với trận lũ tháng 9/2009, do trước đó 47 ngày có lượng mưa không đáng kể thì điều kiện ban đầu cũng xấp xỉ như các trận lũ đầu vụ. Kết quả điều kiện ban đầu được lập tại bảng 5 .

Bảng 5. Điều kiện ban đầu của mô hình tại các thời kỳ

\begin{tabular}{ccccccc}
\hline Lưu vực & Thời kỳ & U/Umax & L/Lmax & QOF & QIF & BF \\
\hline Quỳ Châu & Đầu vụ & 0,3 & 0,3 & 10 & 5 & 2 \\
& Giữa vụ & 0,8 & 0,8 & 10 & 5 & 2 \\
& Cuối vụ & 0,8 & 0,8 & 10 & 5 & 2 \\
Sơn Diệm & Đầu vụ & 0,3 & 0,3 & 10 & 5 & 2 \\
& Giữa vụ & 0,8 & 0,8 & 10 & 5 & 2 \\
& Cuối vụ & 0,8 & 0,8 & 10 & 5 & 2 \\
\hline
\end{tabular}


3.3.2. Xác định mô hình mưa gây ngập luu vưc sông $C a ̉$

Theo thống kê các trận lũ tại trạm thủy văn Chợ Tràng, từ năm 2005 đến 2019 có 23 trận lũ xuất hiện ở hạ lưu sông Cả. Trong đó trận lũ lớn nhất xẩy ra vào tháng $10 / 2010\left(\mathrm{H}_{\max }=4.96 \mathrm{~m}\right)$ và trận lũ nhỏ nhất xẩy ra vào tháng 09/2019 $\left(\mathrm{H}_{\max }=2.09 \mathrm{~m}\right)$. Các trận lũ bắt đầu gây ngập hạ du sông Cả có mức nước xấp xỉ $3.00 \mathrm{~m}$ gồm: 08/2005 ( $\left.\mathrm{H}_{\max }=2.76 \mathrm{~m}\right), 09 / 2013\left(\mathrm{H}_{\max }=3.09 \mathrm{~m}\right)$ và $08 / 2012\left(\mathrm{H}_{\max }=3.14 \mathrm{~m}\right)$. Căn cứ vào sự phân bố mưa của trận lũ trên toàn lưu vực chúng tôi chọn trận lũ tháng 09/2013 làm mô hình mưa gây lũ bắt đầu ngập hạ du sông Cả. Đồng thời, nghiên cứu chọn trận mưa gây ngập lớn nhất (tháng 10/2010) làm mô hình mưa gây lũ lớn cho hạ du sông Cả.

3.3.3. Tính toán lượng mưa gây ngập lưu vục sông $C a ̉$

Mức độ ngập lụt ở hạ lưu sông Cả do mưa,

Bảng 6. Mưa định lương gây ngập hạ du sông Cả - Thời kỳ đầu vu (mm)

\begin{tabular}{lccc}
\hline \multicolumn{1}{c}{ Điều kiện lưu vực } & \multicolumn{3}{c}{ Mức độ ngập } \\
\cline { 2 - 4 } & Bắt đầu ngập & Mức BĐ2 & Mức BĐ3 \\
\hline $\begin{array}{l}\text { Tự nhiên } \\
\begin{array}{l}\text { Có vận hành của hệ thống } \\
\text { hồ hiện tại }\end{array}\end{array}$ & 220 & 320 & 400 \\
$\begin{array}{l}\text { Có vận hành của hệ thống } \\
\text { hồ quy hoạch }\end{array}$ & 300 & 415 & 530 \\
\hline
\end{tabular}

Bảng 7. Mura định lương gây ngập hạ du sông Cả thời kỳ giữa và cuối vu (mm) ở điều kiện tụ nhiên

\begin{tabular}{lccc}
\hline \multirow{2}{*}{ Điều kiện lưu vực } & \multicolumn{3}{c}{ Mức độ ngập } \\
\cline { 2 - 4 } & Bắt đầu ngập & Mức BĐ2 & Mức BĐ3 \\
\hline Tự nhiên & 150 & 250 & 330 \\
\hline
\end{tabular}

Bảng 8. Mura định lương bắt đầu gây ngập hạ du sông Cả thời kỳ giữa và cuối vu (mm) khi có sự vận hành của hệ thống hồ chứa

\begin{tabular}{lcccc}
\hline \multicolumn{1}{c}{ Điều kiện lưu vực } & \multicolumn{4}{c}{ Hiện trạng hồ chứa } \\
\cline { 2 - 5 } & $25 \%$ & $50 \%$ & $75 \%$ & $100 \%$ \\
\hline $\begin{array}{l}\text { Có vận hành của hệ } \\
\text { thống hồ hiện tại }\end{array}$ & 285 & 285 & 285 & 280 \\
$\begin{array}{l}\text { Có vận hành của hệ } \\
\text { thống hồ quy hoạch }\end{array}$ & 320 & 320 & 300 & 285 \\
\hline
\end{tabular}




\section{BÀI BÁO KHOA HỌC}

Bảng 9. Mưa định lương gây ngập hạ du sông Cả ở mức BĐ2 thời kỳ giữa và cuối vu (mm) khi có sự vận hành của hệ thống hồ chứa

\begin{tabular}{lllll}
\hline \multirow{2}{*}{ Điều kiện lưu vực } & \multicolumn{4}{c}{ Hiện trạng hồ chứa } \\
\cline { 2 - 5 } & $25 \%$ & $50 \%$ & $75 \%$ & $100 \%$ \\
\hline $\begin{array}{l}\text { Có vận hành của hệ } \\
\text { thống hồ hiện tại }\end{array}$ & 390 & 390 & 375 & 345 \\
$\begin{array}{l}\text { Có vận hành của hệ } \\
\text { thống hồ quy hoạch }\end{array}$ & 460 & 445 & 400 & 355 \\
\hline
\end{tabular}

Bảng 10. Mưa định lượng gây ngập hạ du sông Cả ở mức BĐ3 thời kỳ giũua và cuối vu (mm) khi có sụ̂ vận hành của hệ thống hồ chứa

\begin{tabular}{lcccc}
\hline \multirow{2}{*}{ Điều kiện lưu vực } & \multicolumn{4}{c}{ Hiện trạng hồ chứa } \\
\cline { 2 - 5 } & $25 \%$ & $50 \%$ & $75 \%$ & $100 \%$ \\
\hline $\begin{array}{l}\text { Có vận hành của hệ } \\
\text { thống hồ hiện tại }\end{array}$ & 390 & 390 & 375 & 345 \\
$\begin{array}{l}\text { Có vận hành của hệ } \\
\text { thống hồ quy hoạch }\end{array}$ & 460 & 445 & 400 & 355 \\
\hline
\end{tabular}

\section{Kết luận}

- Nghiên cứu đã mô phỏng lũ thành công để phục vụ tính toán ngập lụt cho hạ du sông Cả và chi tiết 60 tiểu lưu vực tính toán dòng chảy từ MIKE NAM, 17 đoạn sông với 575 mặt cắt ngang vào sơ đồ tính toán MIKE 11 , và đã rời rạc hóa vùng ngập lụt thành 89.861 phần tử hữu hạn với diện tích $3.200 \mathrm{~km}^{2}$ cho MIKE 21. Kết quả cho thấy quá trình mực nước tính toán và thực đo tại 03 điểm so sánh rất phù hợp nhau, độ lớn và thời gian xuất hiện đỉnh lũ gần nhau $(\Delta \mathrm{H}$ $<0,3 \mathrm{~m}$ ), hệ số Nash đều đạt được trị số cao (Nash $>0,89)$. Riêng sai số tổng lượng còn để lại khá lớn (tại Linh Cảm: $\Delta \mathrm{W}=10 \%$ ). Có thể sử dụng mô hình này để tính toán dự báo ngập lụt, nâng cao chất lượng dự báo lũ, ngập lụt ở hạ du sông Cả.

- Nghiên cứu đã xác định được điều kiện ban đầu của mô hình và đã tính toán được lượng mưa định tính gây ngập lụt ở hạ du sông Cả trong các trường hợp: bắt đầu gây ngập, ngập ở mức báo động 2 và 3 trong điều kiện tự nhiên và có sự vận hành của hệ thống hồ chứa hiện tại và quy hoạch. Kết quả của nghiên cứu có thể sử dụng trong công tác phòng nhẹ thiên tai và giảm nhẹ thiệt hạ do ngập lụt gây ra ở hạ du lưu vực sông Cả.

\section{Tài liệu tham khảo}

1. Lương Tuấn Anh, Trần Ngọc Anh, Trần Văn Đạt, Nguyễn Tiền Giang, Nguyễn Quanh Hưng, Đặng Đình Khá, Trịnh Minh Ngọc, Nguyễn Thanh Sơn, Ngô Chí Tuấn, Cấn Thu Văn (2015), Bản đồ ngập lut và bản đồ đánh giá mức độ dễ bị tổn thương do lũ trên các lưu vực sông: Lam, Bến Hải - Thạch Hãn và Thu Bồn. Nhà xuất bản Khoa học và Kỹ thuật.

2. Tran Tho Dat, Doan Quang Tri, Dinh Duc Truong, Nguyen Ngoc Hoa (2019), Application of Mike Flood Model in Inundation Simulation with the Dam-break Scenarios: a Case Study of DakDrinh Reservoir in Vietnam. International Journal of Earth Sciences and Engineering, 12 (01), 6070. DOI:10.21276/ijee.2019.12.0106.

3. Trần Duy Kiều (2012), Nghiên cứu quản lý lũ lớn lưu vực sông Lam. Luận án Tiến sỹ.

4. Nguyen Thi Mai Linh, Doan Quang Tri, Tran Hong Thai, Nguyen Cao Don (2018), Application of a two-dimensional model for flooding and floodplain simulation: Case study in Tra KhucSong Ve river in Viet Nam. Lowland Technology International, 20 (3), 367-378.

5. Hoàng Thị Nguyệt Minh (2014), Nghiên cứu co sở khoa học và đề xuất giải pháp tiêu úng, thoát lũ sông Phan - Cà Lồ. Luận án tiến sĩ. 
6. Nguyễn Thanh Sơn, Trần Ngọc Anh, Đặng Đình Khá, Nguyễn Xuân Tiến, Lê Viết Thìn (2014), Thư nghiệm đánh giá tác động của Biến đổi khí hậu đến ngập lụt khu vục hạ lưu sông Lam. Tạp chí Khí tượng Thủy văn, 645, 13-20.

7. Tran Hong Thai, Doan Quang Tri (2019), Combination of hydrologic and hydraulic modeling on flood and inundation warning: case study at Tra Khuc-Ve river basin in Vietnam. Vietnam Journal of Earth Sciences, 41 (3), 240-251. Doi: 10.15625/0866-7187/41/3/13866.

8. Hoàng Thanh Tùng (2011), Nghiên cưu dụ báo mura, lũ trung hạn cho vận hành hệ thống hồ chứa phòng lũ - úng dụng cho lưu vực sông Cả. Luận án tiến sĩ.

9. DHI (2009), MIKE 11 Reference Manual, Hydrodynamic Module Scientific Documentation, MIKE by DHI.

10. DHI (2009), MIKE 21 Flow Model, Hydrodynamic Module Scientific Documentation, MIKE by DHI.

11. Knebla, M.R., Yanga, Z.L., Hutchisonb, K., Maidment, D.R., (2005), Regional scale flood modeling using NEXRAD rainfall, GIS, and HEC-HMS/RAS: a case study for the San Antonio River Basin Summer 2002 storm event. Journal of Environmental Management, 75 (4), 325-336.

12. Nguyen, M.D., (2010), Intergrated flood risk assessment for the Day river flood diversion area in the Red river, Vietnam. $\mathrm{PhD}$ dissertation of engineering in water engineering and management. AIT 2010.

13. Nielsen, C., (2006), The application of MIKE SHE to floodplain inundation and urban drainage assessment in South East Asia. DHI Water and Environment (Malaysia).

14. Pathiraa, A., Tsegaye, S., Gersonius, B., Vairavamoorthy, K., (2011), A simple 2-D inundation model for incorporating flood damage in urban planning. Hydrology and Earth System Science, 15, 2747-2761. Doi:10.5194/hess-15-2747-2011.

15. Tomkratoke, S., Sirisup, S., (2015), Hydrodynamic simulation of overland flooding over lowlying flat lands: A case study of the severe 2011 flood in Sam-Khok and Klong Luang districts, Thailand. Hydrological Research Letters, 9 (4), 47-53.

\title{
APPLICATION OF HYDROLOGIC AND HYDRAULIC MODELING FOR FLOOD INUNDATION SIMULATION ON DOWNSTREAM OF THE CA RIVER
}

\author{
Nguyen Xuan Tien ${ }^{1}$, Nguyen Thanh Son ${ }^{2}$, Nguyen Van Linh ${ }^{3}$ \\ ${ }^{1}$ Northern central regional Hydro-Meteorological Center \\ ${ }^{2}$ Faculty of Meteorology, Hydrology and Oceanography - VNU University of Science \\ ${ }^{3}$ Faculty of Hydrology -Thuyloi University, HaNoi
}

\begin{abstract}
Due to the impact of climate change and the development of the irrigation and hydropower systems in the upstream of Ca river basin, downstream-flooding problems are becoming more and more serious. As a result, a finding of the causes of flooding in this paper to provide appropriate solutions to reduce damage is urgent nowadays. This article presents the application of MIKE model, including MIKE NAM, MIKE 11 and MIKE 21, to set-up and to simulate flood-modeling in the downstream of the Ca basin river. This paper uses 14-year hydro-meteorological data (from 2005 to 2018) at 30 stations with 6-hour rainy period to calibrate and test. The comparison between observed and simulated values of water level at three stations is similar; magnitudes and times of occurrence of flood peak are close to each other $(\Delta H<0.3 \mathrm{~m})$. Nash-Sutcliffe coefficients all achieve high values (Nash > 0.89). The study showed the amount of rainfall that caused inundation at flood-alerted levels (level 2 and 3) in natural conditions and the impact of the reservoir on the Ca river system.
\end{abstract}

Keywords: Ca River, Mike NAM, MIKE 11, MIKE 21 models, Inundation. 